\title{
Valuation on an Outside-Reset Option with Multiple Resettable Levels and Dates
}

\author{
Guangming Xue, ${ }^{1}$ Bin Qin, ${ }^{1}$ and Guohe Deng $\mathbb{D}^{2}$ \\ ${ }^{1}$ School of Information and Statistics, Guangxi University of Finance and Economics, Nanning 530003, China \\ ${ }^{2}$ School of Mathematics and Statistics, Guangxi Normal University, Guilin 541004, China
}

Correspondence should be addressed to Guohe Deng; dengguohe@mailbox.gxnu.edu.cn

Received 14 October 2017; Accepted 22 February 2018; Published 8 April 2018

Academic Editor: Michele Scarpiniti

Copyright (c) 2018 Guangming Xue et al. This is an open access article distributed under the Creative Commons Attribution License, which permits unrestricted use, distribution, and reproduction in any medium, provided the original work is properly cited.

This paper studies an outside-reset option with multiple strike resets and reset dates, in which the strike price is adjusted by an external process associated with the underlying risky asset. We obtain analytical pricing formula for this option and the hedging parameters Delta and Gamma. Furthermore, some numerical examples are provided to analyze some characteristics of the outsidereset option and to examine the impacts of the external parameters on option prices and Greeks. These results show that the external process can significantly affect option prices and Greeks.

\section{Introduction}

Reset options, whose strike price will be adjusted to a new strike price only on each of a set of prespecified dates if the stock price is below one of the reset levels, have greatly evolved in the past two decades. This reset clause embedded in derivative products can protect the investors amidst stock price declines. This makes a reset option useful in portfolio insurance (see, e.g., Boyle et al. [1]).

There are only a few articles studying the reset options in the academic literature. Gray and Whaley [2] were the first ones to examine the value of S\&P 500 index bear market warrants with a periodic reset feature. In their other paper (see Gray and Whaley [3]), they provided an explicit formula for the reset option with a periodic reset date. Hsueh and Guo [4], on the other hand, analyzed the multiple reset feature that is included in most covered warrants traded in Taiwan. More recently, Cheng and Zhang [5] discussed the pricing and hedging of reset options and propose a closedform pricing formula for this increasingly popular derivative instrument. Li et al. [6] derived a generalization of price formula for the reset call options with predetermined rates when the spot interest rate and volatility of stock are all time-dependent and deterministic. Liu et al. [7] evaluated the pricing of reset options when the underlying assets are autocorrelated. François-Heude and Yousfi [8] proposed a general valuation of reset option studied in Gray and Whaley [2] in which all options are replaced by ATM (At-The-Money) ones. Subsequent contributions include analytic extensions to multiple reset rights with shouting moment of Dai et al. $[9,10]$, Dai and Kwok [11], Yang et al. [12], and Goard [13], step (or snapshot)-reset design of Hsueh and Liu [14], and Yu and Shaw [15], average trigger reset clauses of Kao and Lyuu [16], Liao and Wang [17], Kim et al. [18], Chang et al. [19], Dai et al. [20], and Costabile et al. [21, 22], window reset option with continuous reset constraints of Hsiao [23], and reset rights embedded in the Quanto options of Chen and Jiang [24].

In general, the reset call option with $m$ predetermined reset dates $0<t_{1}<t_{2}<\cdots<t_{m}<T$ has a payoff at a fixed maturity $T$ of

$$
V(T)=\max \left\{S_{T}-\min \left[K_{0}, S_{t_{1}}, S_{t_{2}}, \ldots, S_{t_{m}}\right], 0\right\},
$$

where $S_{t}$ denotes the underlying asset price at time $t$ and $K_{0}$ denotes the initial strike price of option. In a real application, the terminal payoff of reset call option is usually set as

$$
V(T)=\max \left\{S_{T}-K^{*}, 0\right\}=\left(S_{T}-K^{*}\right)^{+},
$$


where $K^{*}$ is defined by

$$
K^{*}= \begin{cases}K_{0}, & \text { if } \min \left[S_{t_{1}}, S_{t_{2}}, \ldots, S_{t_{m}}\right] \geq D_{1}, \\ K_{j}, & \text { if } D_{j}>\min \left[S_{t_{1}}, S_{t_{2}}, \ldots, S_{t_{m}}\right] \geq D_{j+1}, j=1,2, \ldots, d-1, \\ K_{d}, & \text { if } D_{d}>\min \left[S_{t_{1}}, S_{t_{2}}, \ldots, S_{t_{m}}\right]\end{cases}
$$

where $K_{j}, j=1,2, \ldots, d$, denote the strike price resets such that $K_{0}>K_{1}>K_{2}>\cdots>K_{d}>0$ and $D_{j}, j=1,2, \ldots, d$, are the reset levels. In particular, there is only one reset price when $d=1$. For valuation on the general-reset options, Liao and Wang [25] provided an explicit pricing formula of this option and analyzed the phenomena of Delta jump and Gamma jump across reset dates. In fact, there is essentially no explicit pricing formula for the discrete reset options, except when they resort to multivariate cumulative normal distribution function.

A common disadvantage of the reset option whose payoff is defined in (1), however, is that the reset trigger depends on the underlying asset price alone. This exposes the holder and the writer of the reset option to the risk that the counterparty may manipulate the underlying asset price such that the payoff of the reset option being benefits according to the counterparty favorable way. In other words, the strike price reset event is triggered by a price fluctuation intentionally caused by the counterparty. In order to prevent such price manipulation, reset options have been innovated where the trigger event does not depend on the underlying asset price but on an external variable $Y_{t}$. For example, the underlying asset may be a foreign stock and the external variable may be an average of the underlying asset, the exchange rate or another asset correlating with the underlying asset. We will study different reset conditions imposed on a distinct but correlated underlying asset process. Such reset conditions are often called outside resets (see Heynen and Kat [26] and Kwok et al. [27]), and they are rather less studied than the regular type defined in (1). In this paper we propose an outside-reset option where the strike price $K^{*}$ is replaced by

$$
K^{*}= \begin{cases}K_{0}, & \text { if } \min \left[Y_{t_{1}}, Y_{t_{2}}, \ldots, Y_{t_{m}}\right] \geq D_{1} \\ K_{j}, & \text { if } D_{j}>\min \left[Y_{t_{1}}, Y_{t_{2}}, \ldots, Y_{t_{m}}\right] \geq D_{j+1}, j=1,2, \ldots, d-1, \\ K_{d}, & \text { if } D_{d}>\min \left[Y_{t_{1}}, Y_{t_{2}}, \ldots, Y_{t_{m}}\right]\end{cases}
$$

This novel design of using the external variable $Y_{t}$ as a reset trigger replacing the underlying asset $S_{t}$, as in the general-reset option specified in (2) and (3), offers three important advantages to both issuers and investors. First, the outside-reset option reduces the price manipulation around the reset level. Second, the outside-reset specification rules out jumps in Delta and thus makes the reset option more amenable to dynamic hedging. Finally, the outside-reset option provides a strike price correlated with an external variable fluctuation. The payoff that comes with these mentioned advantages above is complexity. The outside-reset option contains a simultaneous generalization of the reset option discussed by Liao and Wang [25] and a multivariate-based option of which both have a number of useful applications. For example, the arithmetic average reset options listed on the Taiwan Stock Exchange used an average of the stock prices as a trigger variable for reset. A barrier option on one or multiple assets with single external barrier also used other assets as resettable barrier variables for determining whether the options knock in or out. For valuation on these options, one can look to Cheng and Zhang [5], Liao and Wang [17], Kim et al. [18], Costabile et al. [22], Zhang [28], and so forth.
This paper is to discuss the pricing problem of the outside-reset option, defined by (2) and (4), and has two contributions. The first is to derive the analytical pricing formula for the outside-reset option under the proposed model. Furthermore, we provide the analytical pricing formula for the outside-reset option with $d$ strike resets and continuous reset dates, which is the limiting case of that with a set of discrete reset dates, and the hedging parameters Delta and Gamma. The second is to analyze the impacts of the external process on the option price and the values of Delta and Gamma and the phenomena of Delta and Gamma jumps across reset dates using numerical experiments.

The paper is organized as follows: in Section 2, a closedform pricing formula is derived first for the outside-reset option under the assumption that the underlying asset price process and the external process follow two correlation geometric Brownian motions. In Section 3, we discuss some properties of the outside-reset option and present our numerical results. Finally, in Section 4, we give conclusion remarks and directions of future research. 


\section{The Proposed Model and Pricing Outside-Reset Option}

Following Heynen and Kat [26], we consider the two stochastic differential equations for the underlying risky asset price $S_{t}$ and the external process $Y_{t}$ (as a reset trigger) under a riskneutral measure $Q$ :

$$
\begin{aligned}
& \frac{d Y_{t}}{Y_{t}}=r d t+\sigma_{1} d W_{t}^{1}, \\
& \frac{d S_{t}}{S_{t}}=r d t+\rho \sigma_{2} d W_{t}^{1}+\sqrt{1-\rho^{2}} \sigma_{2} d W_{t}^{2},
\end{aligned}
$$

where $\sigma_{1}>0, \sigma_{2}>0$, and $-1 \leq \rho \leq 1$ are constants, and $W_{t}=$ $\left(W_{t}^{1}, W_{t}^{2}\right)$ is a bidimensional standard Brownian motion defined on a filtered probability space $\left(\Omega, \mathscr{F},\left(\mathscr{F}_{t}\right)_{0 \leq t \leq T}, Q\right)$, where $\left(\mathscr{F}_{t}\right)_{0 \leq t \leq T}$ is the $Q$-augmentation of the filtration generated by $W_{t}$ and satisfies the usual conditions, $r \geq 0$ is the constant risk-free interest rate, and $\rho$ presents the correlation coefficient between $S_{t}$ and $Y_{t}$. It should be noted that model (5) may reduce to the results discussed by Liao and Wang [25] for the case when $\sigma_{1}=\sigma_{2}$ and $\rho=1$.

Using Itô formula to model (5), then, for $t<s$,

$$
\begin{aligned}
Y_{s} & =Y_{t} \exp \left\{\left(r-\frac{1}{2} \sigma_{1}^{2}\right)(s-t)+\sigma_{1}\left(W_{s}^{1}-W_{t}^{1}\right)\right\}, \\
S_{s} & =S_{t} \exp \left\{\left(r-\frac{1}{2} \sigma_{2}^{2}\right)(s-t)+\rho \sigma_{2}\left(W_{s}^{1}-W_{t}^{1}\right)\right. \\
& \left.+\sqrt{1-\rho^{2}} \sigma_{2}\left(W_{s}^{2}-W_{t}^{2}\right)\right\} .
\end{aligned}
$$

In view of (2) and (4), the terminal payoff of the outsidereset option with $d$ strike resets and $m$ predetermined reset dates can be written as

$$
\begin{aligned}
V(T)= & \left(S_{T}-K_{0}\right)^{+} I_{A_{1}}+\left(S_{T}-K_{1}\right)^{+}\left(I_{A_{2}}-I_{A_{1}}\right)+\cdots \\
& +\left(S_{T}-K_{d-1}\right)^{+}\left(I_{A_{d}}-I_{A_{d-1}}\right) \\
& +\left(S_{T}-K_{d}\right)^{+}\left(1-I_{A_{d}}\right),
\end{aligned}
$$

where $A_{j}=\left\{\min \left[Y_{t_{1}}, Y_{t_{2}}, \ldots, Y_{t_{m}}\right] \geq D_{j}\right\}, j \in\{1,2, \ldots, d\}$, and $I(\cdot)$ is indicator function. Following the pricing theory, under the risk-neutral measure $Q$, the value at time $t$ of the outside-reset option is

$$
\begin{aligned}
\operatorname{ORC}(t)= & E^{\mathrm{Q}}\left\{e^{-r(T-t)} V(T) \mid \mathscr{F}_{t}\right\} \\
= & E_{t}^{\mathrm{Q}}\left\{e^{-r(T-t)} V(T)\right\} \\
= & \sum_{l=1}^{d} E_{t}^{\mathrm{Q}}\left\{e^{-r(T-t)}\left(S_{T}-K_{l-1}\right)^{+} I_{A_{l}}\right\} \\
& -\sum_{l=1}^{d} E_{t}^{\mathrm{Q}}\left\{e^{-r(T-t)}\left(S_{T}-K_{l}\right)^{+} I_{A_{l}}\right\} \\
& +E_{t}^{\mathrm{Q}}\left\{e^{-r(T-t)}\left(S_{T}-K_{d}\right)^{+}\right\},
\end{aligned}
$$

where $0 \leq t<t_{1}<t_{2}<\cdots<t_{m}<T$.
From (8), we know that the key of solution is to compute the following expression:

$$
E_{t}^{Q}\left\{e^{-r(T-t)}\left(S_{T}-K_{h}\right)^{+} I_{A_{l}}\right\}
$$

where $h=l-1$ or $l$. Now we present the result in the following proposition.

Proposition 1. The value at time $t$ of the expression, $E_{t}^{\mathrm{Q}}\left\{e^{-r(T-t)}\left(S_{T}-K_{h}\right)^{+} I_{A_{l}}\right\}$, assuming the risky asset price given in the model (5), is

$$
\sum_{g=1}^{m}\left[S_{t} N_{m+1}\left(D_{g}^{l, h} ; \Sigma_{g}\right)-K_{h} e^{-r(T-t)} N_{m+1}\left(\bar{D}_{g}^{l, h} ; \Sigma_{g}\right)\right]
$$

where $N_{m+1}(\cdot ; \Sigma)$ is the $(m+1)$-dimensional cumulative normal distribution function with mean vector 0 and correlation matrix $\Sigma$, and $D_{g}^{l, h}$ stands for the transpose of the gth row of matrix $D^{l, h}$ as follows:

$$
D^{l, h}=\left(\begin{array}{cccccc}
a_{l, 1} & b_{1,2} & b_{1,3} & \cdots & b_{1, m} & d_{h} \\
b_{2,1} & a_{l, 2} & b_{2,3} & \cdots & b_{2, m} & d_{h} \\
b_{3,1} & b_{3,2} & a_{l, 3} & \cdots & b_{3, m} & d_{h} \\
\vdots & \vdots & \ddots & \vdots & \vdots & \\
b_{m, 1} & b_{m, 2} & b_{m, 3} & \cdots & a_{l, m} & d_{h}
\end{array}\right)_{m \times(m+1)}
$$

The components of the matrix $D^{l, h}$ are defined as follows:

$$
\begin{aligned}
a_{l, g} & =\frac{\ln \left(Y_{t} / D_{l}\right)+\left(r-(1 / 2) \sigma_{1}^{2}+\rho \sigma_{1} \sigma_{2}\right)\left(t_{g}-t\right)}{\sigma_{1} \sqrt{t_{g}-t}}, \\
b_{g, j} & =\frac{\left(r-(1 / 2) \sigma_{1}^{2}+\rho \sigma_{1} \sigma_{2}\right)\left(t_{j}-t_{g}\right)}{\sigma_{1} \sqrt{\left|t_{j}-t_{g}\right|}}, \\
d_{h} & =\frac{\ln \left(S_{t} / K_{h}\right)+\left(r+(1 / 2) \sigma_{2}^{2}\right)(T-t)}{\sigma_{2} \sqrt{T-t}} .
\end{aligned}
$$

The components of the matrix $\bar{D}^{l, h}$ are the same as those of the ones of the matrix $D^{l, h}$ except the components $a_{l, g}, b_{g, j}$, and $d_{h}$ are replaced by $\bar{a}_{l, g}, \bar{b}_{g, j}$, and $\bar{d}_{h}$, respectively. Here

$$
\begin{aligned}
& \bar{a}_{l, g}=a_{l, g}-\rho \sigma_{2} \sqrt{t_{g}-t}, \\
& \bar{b}_{g, j}=\frac{\left(r-(1 / 2) \sigma_{1}^{2}\right)\left(t_{j}-t_{g}\right)}{\sigma_{1} \sqrt{\left|t_{j}-t_{g}\right|}}, \\
& \bar{d}_{h}=d_{h}-\sigma_{2} \sqrt{T-t} .
\end{aligned}
$$


The correlation matrix $\Sigma_{g}=\left(\rho_{k, j}^{g}\right)_{(m+1) \times(m+1)}, k, j=1,2$, $\ldots, m+1$, where $\rho_{k, j}^{g}$ is given by

$$
\begin{aligned}
& \rho_{k, j}^{g}=\rho_{j, k}^{g} \\
& = \begin{cases}1, & k=j, \\
\sqrt{\mid \frac{t_{g}-t_{j} \mid}{t_{g}-t_{k} \mid},} & 1 \leq k<j \leq g-1, \text { or } g+1 \leq k<j \leq m, \\
-\sqrt{\frac{t_{g}-t_{k}}{t_{g}-t}}, & 1 \leq k \leq g-1, j=g, \\
-\rho \sqrt{\frac{t_{g}-t_{k}}{T-t}}, & 1 \leq k \leq g-1, j=m+1, \\
\rho \sqrt{\frac{t_{g}-t}{T-t},} & k=g, j=m+1, \\
\rho \sqrt{\frac{t_{k}-t_{g}}{T-t}}, & g+1 \leq k \leq m, j=m+1, \\
0, & \text { otherwise. }\end{cases}
\end{aligned}
$$

Proof. See Appendix A.

It is noticed that the $3 \mathrm{rd}$ term in the right hand of (8) is the value of the European vanilla call option given by BlackScholes formula. In view of (10) and (8), the closed-form pricing formula at time $t$ for the outside-reset option is gained by the following proposition.

Proposition 2. The price at time t of the outside-reset option with $m$-periodic reset and $d$ strike resets, assuming the risky asset price given in model (5), is

$$
\begin{aligned}
& \text { ORC }(t)=S_{t}\left\{N\left(d_{d}\right)\right. \\
& \left.+\sum_{l=1}^{d} \sum_{g=1}^{m}\left[N_{m+1}\left(D_{g}^{l, l-1} ; \Sigma_{g}\right)-N_{m+1}\left(D_{g}^{l, l} ; \Sigma_{g}\right)\right]\right\} \\
& -e^{-r(T-t)}\left\{K_{d} N\left(\bar{d}_{d}\right)\right. \\
& \left.\quad+\sum_{l=1}^{d} \sum_{g=1}^{m}\left[K_{l-1} N_{m+1}\left(\bar{D}_{g}^{l, l-1} ; \Sigma_{g}\right)-K_{l} N_{m+1}\left(\bar{D}_{g}^{l, l} ; \Sigma_{g}\right)\right]\right\}
\end{aligned}
$$

where $N(\cdot)$ is the cumulative probability function of a standard normal variable.

The numerical valuation of $N_{m+1}(\cdot ; \Sigma)$ appearing in the analytic formula (15) (where $m$ may take value beyond 100) can be very computationally demanding. Monte Carlo and Quasi-Monte Carlo simulation methods seem to be the most promising for higher-order probabilities. Genz [29] proposed a quasi-randomized Monte Carlo procedure to evaluate the multivariate normal probabilities. Boyle et al. [30] and Lai [31] applied the Quasi-Monte Carlo simulation methods to finance. In this paper, we use Genz's method to compute the cumulative multivariate probability function in (15).

\section{Characteristics of the Outside-Reset Option}

In this section, we will analyze some characteristics of outside-reset option with the implementation of the pricing formula (15) given in Section 2. We then report some numerical results to illustrate the changes of option price with different parameters value in the model and the impacts of parameters of the external process on the option price. We also provide explicit closed-form formula for the outsidereset option with $d$ strike resets and continuous reset dates and the hedging parameters Delta and Gamma. Finally, we analyze the phenomena of Delta jumps and Gamma jumps across reset dates.

3.1. Reset Features of the Outside-Reset Option. First, we discuss some properties of outside-reset option. In what follows, we let the current time $t=0$, the maturity $T=1$ (year), and initial strike price $K_{0}=100$ of the outside-reset option. The strike price $K_{j}, j=1,2, \ldots, d$, will be adjusted if the value of the external process $Y_{t}$ falls below the strike resets $D_{j}$. We will calculate the values of the outside-reset option with one strike reset and two strike resets under three reset dates, respectively. Three reset dates are assumed to be $t_{1}=1 / 12$ (year), $t_{2}=2 / 12$ (year), and $t_{3}=3 / 12$ (year). These results are presented in Tables 1 and 2.

From Tables 1 and 2, we can see that some characteristics of the outside-reset option are similar to the general-reset option studied by Liao and Wang [25]. For example, the values of the outside-reset call option are increasing functions of stock price, risk-free interest rate, and volatility of stock returns, and they are also increasing with the numbers of reset dates. In addition, under the same reset levels $D_{j}$, lower reset strike prices $K_{j}$ will result in higher option values. Due to the higher protection to the option holder, the values of the outside-reset call option with two strike resets are always greater than that with one strike reset under the same model parameter values.

3.2. Impacts of Parameters of External Process on Outside-Reset Option. Next, we investigate the impacts of three parameters including the initial inputs $Y_{0}$, volatility $\sigma_{1}$, and correlation coefficient $\rho$ in the external process on the option price. In Figures 1, 2, and 3, the left panel depicts the option value with one strike reset $(d=1)$ and the right panel depicts the option value with two strike resets $(d=2)$.

In Figure 1, we compare option values as a function of initial inputs $Y_{0}$ with $d(=1,2)$ strike resets and $m(=1,2,3)$ reset dates. Assume that the model parameters are $S_{0}=100$, $r=0.05, \sigma_{1}=0.3, \sigma_{2}=0.3, K_{1}=95, K_{2}=85, D_{1}=90$, $D_{2}=80$, and $\rho=1$. From Figure 1, we see that the option values decrease as $Y_{0}$ increases for any reset dates. Also, we see that the outside-reset option value decreases more rapidly when the value of $Y_{0}$ is in the interval $[75,110]$. However, the change is very little for $Y_{0}<75$, which reduces the price manipulation around the reset level. 
TABLE 1: Values of the outside-reset option with single strike reset and three reset dates.

\begin{tabular}{|c|c|c|c|c|c|c|c|c|}
\hline \multirow{3}{*}{$\sigma_{2}$} & \multirow{3}{*}{$S_{0}$} & \multirow{3}{*}{$K_{1}$} & \multirow{2}{*}{\multicolumn{3}{|c|}{$\begin{array}{c}r=0.05 \\
m\end{array}$}} & \multirow{2}{*}{\multicolumn{3}{|c|}{$\begin{array}{c}r=0.07 \\
m\end{array}$}} \\
\hline & & & & & & & & \\
\hline & & & 1 & 2 & 3 & 1 & 2 & 3 \\
\hline \multirow{6}{*}{0.1} & \multirow{3}{*}{85} & 85 & 1.0983 & 1.3492 & 2.5126 & 1.4386 & 2.0270 & 3.0660 \\
\hline & & 90 & 0.8019 & 0.8264 & 1.4968 & 1.1419 & 1.3303 & 1.9530 \\
\hline & & 95 & 0.6658 & 0.6714 & 0.8900 & 0.9536 & 1.0532 & 1.2390 \\
\hline & \multirow{3}{*}{100} & 85 & 8.1683 & 8.4090 & 11.7214 & 9.4943 & 9.6839 & 13.0503 \\
\hline & & 90 & 7.6661 & 7.6884 & 9.8844 & 9.0126 & 9.0186 & 11.2641 \\
\hline & & 95 & 7.1837 & 7.5695 & 8.2075 & 8.5298 & 8.5466 & 9.5928 \\
\hline \multirow{6}{*}{0.3} & \multirow{3}{*}{85} & 85 & 6.9739 & 7.5350 & 8.5148 & 7.5683 & 8.1354 & 9.1442 \\
\hline & & 90 & 6.7524 & 7.0896 & 7.6832 & 7.3454 & 7.6879 & 8.3018 \\
\hline & & 95 & 6.5682 & 6.7199 & 6.9890 & 7.1584 & 7.3132 & 7.5928 \\
\hline & \multirow{3}{*}{100} & 85 & 15.1206 & 16.0240 & 17.5469 & 16.0921 & 16.9846 & 18.5190 \\
\hline & & 90 & 14.7867 & 15.3503 & 16.3057 & 15.7632 & 16.3221 & 17.2882 \\
\hline & & 95 & 14.4905 & 14.7533 & 15.2013 & 15.4695 & 15.7311 & 16.1858 \\
\hline
\end{tabular}

The parameters are $\sigma_{1}=0.3, \rho=0.25, Y_{0}=100$, and $D_{1}=90$.

TABLE 2: Values of the outside reset option with two strike resets and three reset dates.

\begin{tabular}{|c|c|c|c|c|c|c|c|c|}
\hline \multirow{3}{*}{$\sigma_{2}$} & \multirow{3}{*}{$S_{0}$} & \multirow{3}{*}{$\left(K_{1}, K_{2}\right)$} & \multirow{2}{*}{\multicolumn{3}{|c|}{$\begin{array}{c}r=0.05 \\
m\end{array}$}} & \multirow{2}{*}{\multicolumn{3}{|c|}{$\begin{array}{c}r=0.07 \\
m\end{array}$}} \\
\hline & & & & & & & & \\
\hline & & & 1 & 2 & 3 & 1 & 2 & 3 \\
\hline \multirow{6}{*}{0.1} & \multirow{3}{*}{85} & $(85,75)$ & 1.1504 & 1.2708 & 4.0516 & 1.4954 & 3.8198 & 4.6219 \\
\hline & & $(90,80)$ & 0.8540 & 0.8784 & 2.6921 & 1.1705 & 1.3878 & 3.2213 \\
\hline & & $(95,85)$ & 0.6836 & 0.6955 & 1.6860 & 0.9731 & 1.2277 & 2.1376 \\
\hline & \multirow{3}{*}{100} & $(85,75)$ & 8.2040 & 8.6264 & 13.5817 & 9.4960 & 9.8386 & 14.8388 \\
\hline & & $(90,80)$ & 7.6975 & 8.0957 & 11.7032 & 9.0367 & 9.3292 & 13.0265 \\
\hline & & $(95,85)$ & 7.2358 & 7.6122 & 9.9175 & 8.6111 & 8.7650 & 11.2795 \\
\hline \multirow{6}{*}{0.3} & \multirow{3}{*}{85} & $(85,75)$ & 6.9973 & 7.7872 & 9.5545 & 7.5911 & 8.4549 & 10.1876 \\
\hline & & $(90,80)$ & 6.7721 & 7.2209 & 8.5729 & 7.3647 & 7.8165 & 9.2021 \\
\hline & & $(95,85)$ & 6.5847 & 6.8278 & 7.7387 & 7.1747 & 7.4199 & 8.3578 \\
\hline & \multirow{3}{*}{100} & $(85,75)$ & 15.1534 & 17.9018 & 18.9530 & 16.1234 & 18.7775 & 19.9037 \\
\hline & & $(90,80)$ & 14.8161 & 15.9776 & 17.5850 & 15.7915 & 18.0760 & 18.5562 \\
\hline & & $(95,85)$ & 14.5166 & 15.6236 & 16.3492 & 15.4948 & 15.6759 & 17.3312 \\
\hline
\end{tabular}

The parameters are $\sigma_{1}=0.3, \rho=0.25, Y_{0}=100, T=1, D_{1}=90$, and $D_{2}=80$.

In Figure 2, we plot option values of the outside-reset calls versus the volatility $\sigma_{1}$ of the external process when the correlated coefficient is $\rho=1$. Assume that the model parameters are $S_{0}=100, r=0.05, Y_{0}=100, \sigma_{2}=0.3$, $K_{1}=95, K_{2}=85, D_{1}=90, D_{2}=80$, and $\rho=1$. The effect on price of the outside-reset option of volatility is remarkable, and option values increase as volatility increases. This is the reason that fluctuation of external process brings the profit opportunity for the option.

Finally, we compare option values as a function of correlation coefficient $\rho$ in Figure 3, in which the model parameters are assumed to be $S_{0}=100, r=0.05, Y_{0}=100$, $\sigma_{1}=0.3, \sigma_{2}=0.3, K_{1}=95, K_{2}=85, D_{1}=90$, and $D_{2}=80$. Figure 3 illustrates that the correlation coefficient influences option value very significantly, and lower values of correlation coefficient will result in higher option values. In addition, if $\sigma_{1}=\sigma_{2}$ and $\rho=1$, then the outside-reset option reduces to the general-reset option studied by Liao and Wang [25]. Therefore, Figure 3 indicates that the option value of outsidereset calls is greater than that of the general-reset calls studied by Liao and Wang [25].

3.3. Outside-Reset Option with Continuous Reset Dates. When $m$ approaches infinity with a remaining time to $T-t$, the set of discrete reset dates become a continuous reset period. From (7), the terminal payoff function of the outside-reset option with continuous reset period is as follows: 


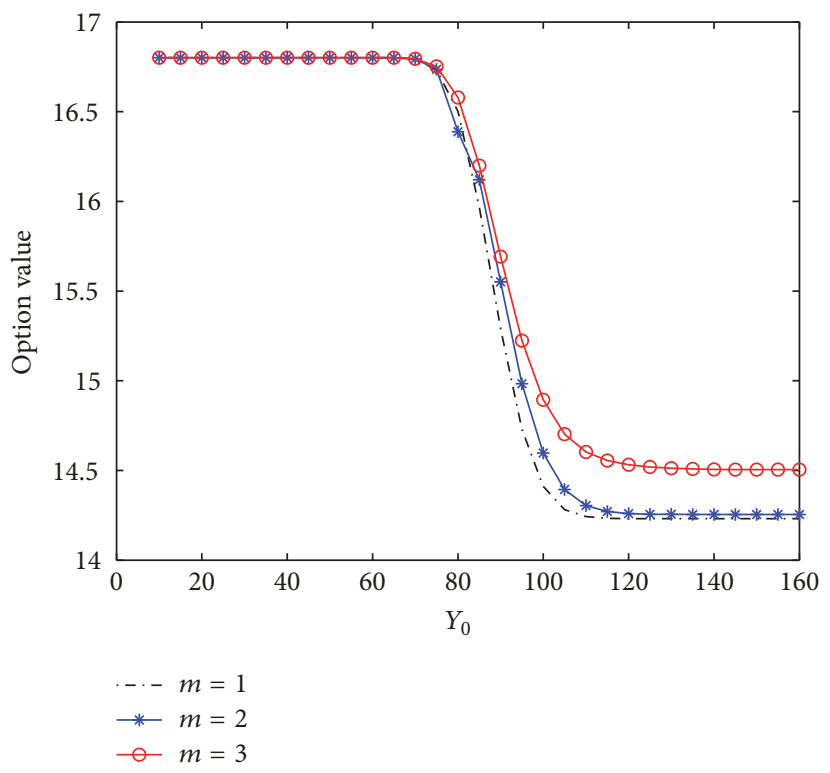

(a) $d=1$

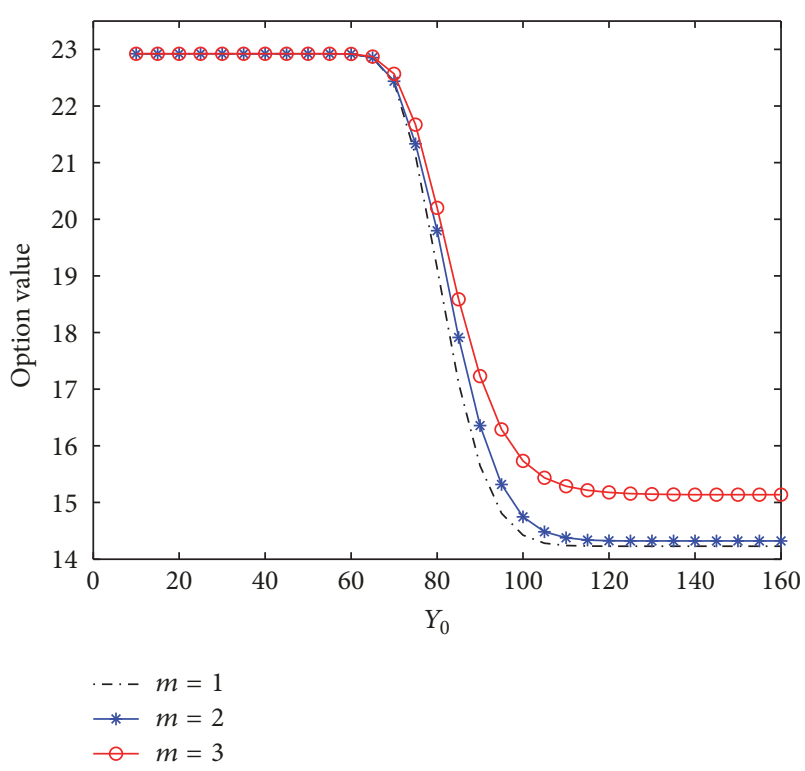

(b) $d=2$

Figure 1: Option values as a function of $Y_{0}$.

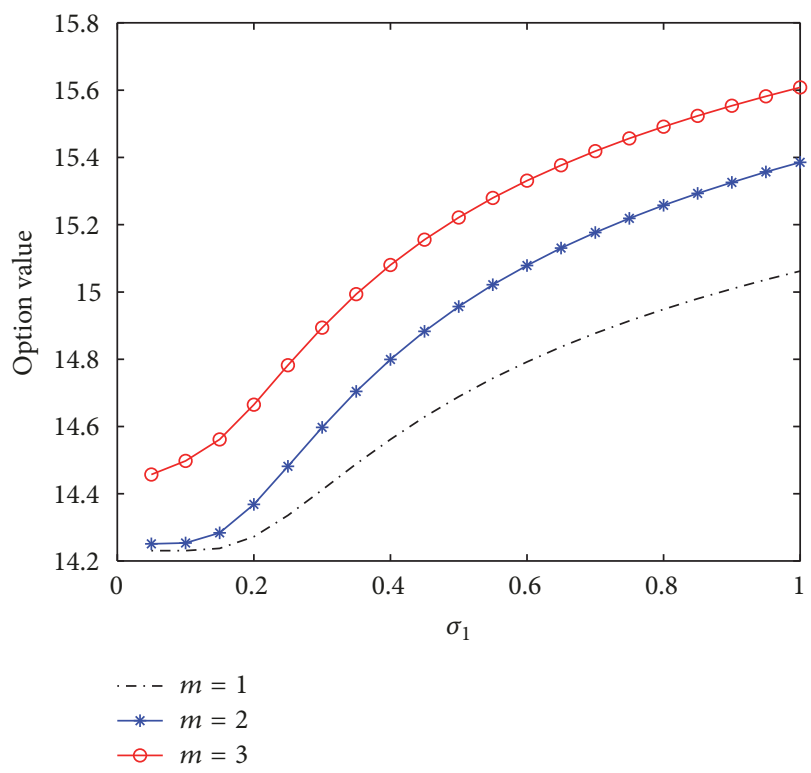

(a) $d=1$

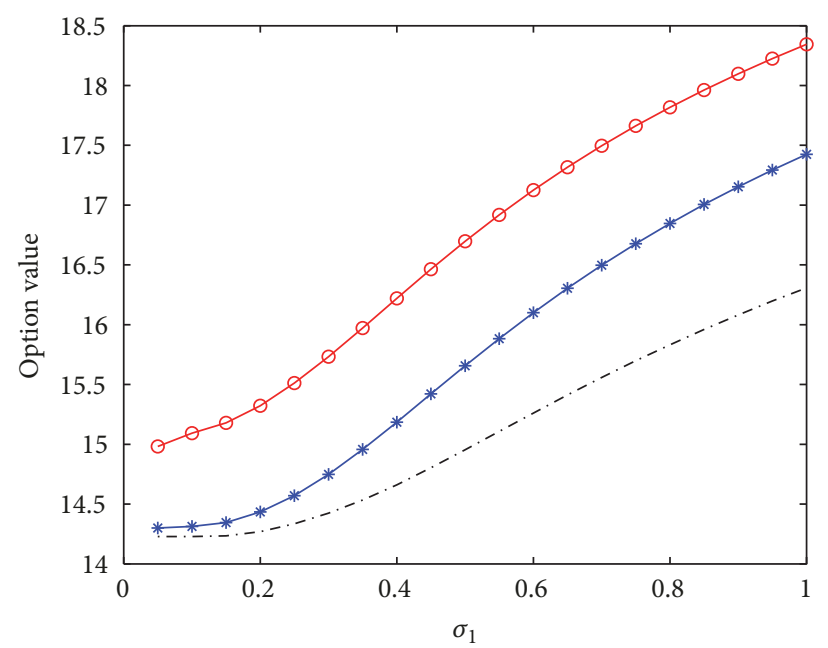

-.. $m=1$

$$
\rightarrow-m=2
$$$$
\multimap m=3
$$

(b) $d=2$

Figure 2: Option values as a function of volatility $\sigma_{1}$.

$$
\begin{aligned}
V(S, Y, T)= & \left(S_{T}-K_{d}\right)^{+} \\
& +\sum_{l=1}^{d}\left(S_{T}-K_{l-1}\right)^{+} I_{\left(\min _{0 \leq t \leq T} Y_{t} \geq D_{l}\right)} \\
& -\sum_{l=1}^{d}\left(S_{T}-K_{l}\right)^{+} I_{\left(\min _{0 \leq t \leq T} Y_{t} \geq D_{l}\right)} .
\end{aligned}
$$

Based on the closed-form formula of European down-andout outside-barrier call option studied by Heynen and Kat
[26], we can present the explicit expression for the outsidereset option with continuous reset period, because

$$
\begin{aligned}
E_{t}^{Q} & \left\{e^{-r(T-t)}\left(S_{T}-K_{h}\right)^{+} I_{\left(\min _{0 \leq t \leq T} Y_{t} \geq D_{l}\right)}\right\} \\
& =S_{t}\left[N_{2}\left(c_{1}^{h},-e_{1}^{l} ; \rho\right)\right. \\
& \left.-\left(\frac{D_{l}}{Y_{t}}\right)^{2\left(r-(1 / 2) \sigma_{1}^{2}+\rho \sigma_{1} \sigma_{2}\right) / \sigma_{1}^{2}} N_{2}\left(\bar{c}_{1}^{h},-\bar{e}_{1}^{l} ; \rho\right)\right]
\end{aligned}
$$




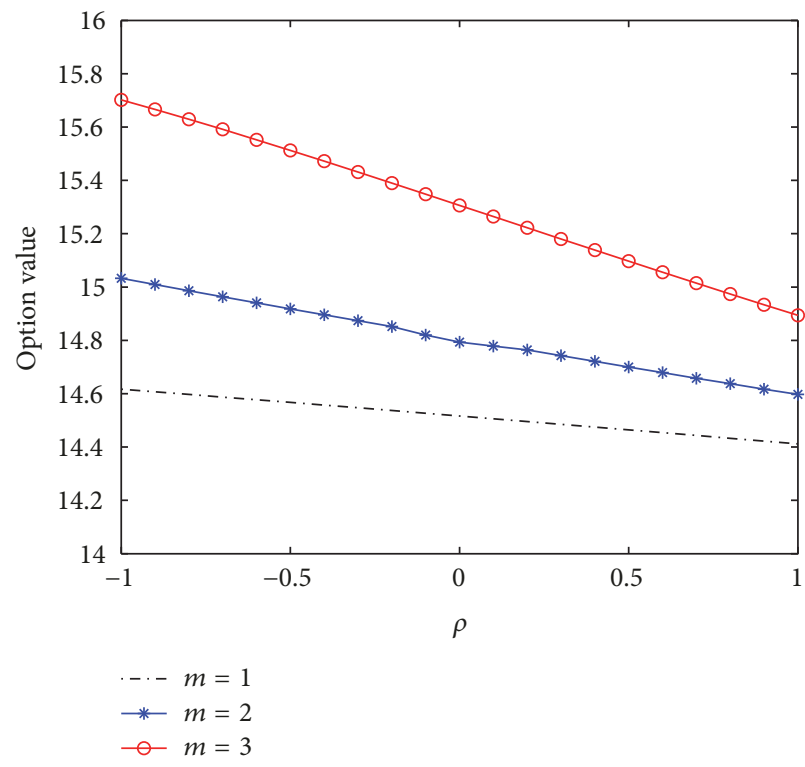

(a) $d=1$

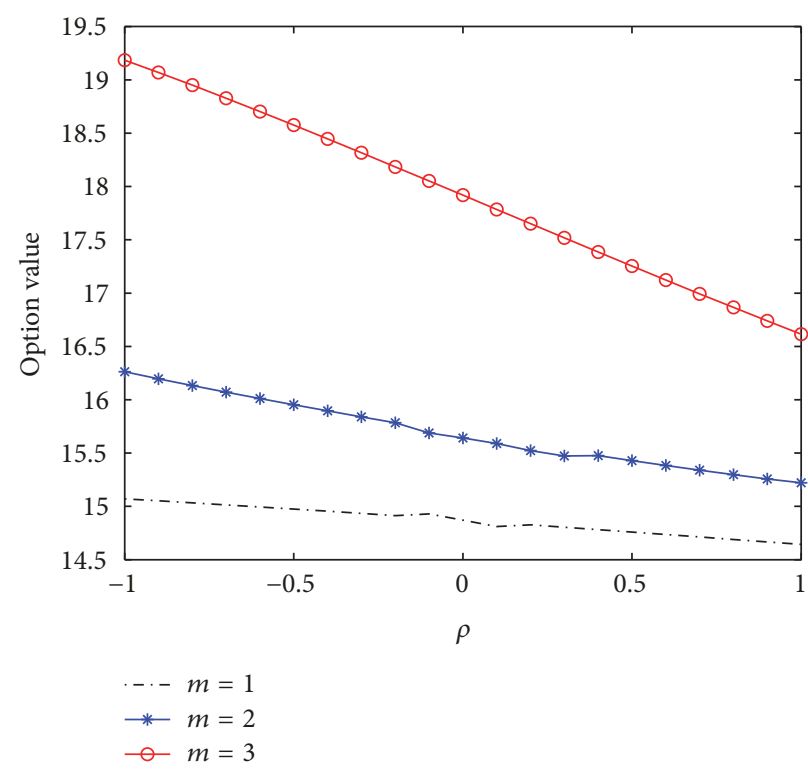

(b) $d=2$

Figure 3: Option values as a function of correlation coefficient $\rho$.

$$
\begin{aligned}
& -e^{-r(T-t)} K_{h}\left[N_{2}\left(c_{2}^{h, l},-e_{2}^{l} ; \rho\right)\right. \\
& \left.-\left(\frac{D_{l}}{Y_{t}}\right)^{2 r / \sigma_{1}^{2}} N_{2}\left(\bar{c}_{2}^{h, l},-\bar{e}_{2}^{l} ; \rho\right)\right],
\end{aligned}
$$

where

$$
\begin{aligned}
c_{1}^{h} & =\frac{\ln \left(S_{t} / K_{h}\right)+\left(r+(1 / 2) \sigma_{2}^{2}\right)(T-t)}{\sigma_{2} \sqrt{T-t}}, \\
c_{1}^{h, l} & =c_{1}^{h}-\sigma_{2} \sqrt{T-t}, \\
\bar{c}_{1}^{h} & =c_{1}^{h}+\frac{2 \rho}{\sigma_{1} \sqrt{T-t}} \ln \frac{D_{l}}{Y_{t}}, \\
\bar{c}_{2}^{h, l} & =\bar{c}_{1}^{h, l}+\frac{2 \rho}{\sigma_{1} \sqrt{T-t}} \ln \frac{D_{l}}{Y_{t}}, \\
e_{1}^{l} & =\frac{\ln \left(D_{l} / Y_{t}\right)-\left(r-(1 / 2) \sigma_{1}^{2}+\rho \sigma_{1} \sigma_{2}\right)(T-t)}{\sigma_{1} \sqrt{T-t}} \\
e_{2}^{l} & =e_{1}^{l}+\rho \sigma_{2} \sqrt{T-t}, \\
\bar{e}_{1}^{l} & =e_{1}^{l}-\frac{2}{\sigma_{1} \sqrt{T-t}} \ln \frac{D_{l}}{Y_{t}}, \\
\bar{e}_{2}^{l} & =\bar{e}_{2}^{l}-\frac{2}{\sigma_{1} \sqrt{T-t}} \ln \frac{D_{l}}{Y_{t}} .
\end{aligned}
$$

Therefore, we present the value at time $t$ of the outsidereset option with continuous reset period in the following proposition.
Proposition 3. The price at time t of the outside-reset option with continuous reset period, assuming the risky asset price given in (5), is given by

$$
\begin{aligned}
& \text { ORCC }(t)=S_{t}\left\{N\left(d_{d}\right)+\sum_{l=1}^{d}\left\{N_{2}\left(c_{1}^{l-1},-e_{1}^{l} ; \rho\right)\right.\right. \\
& -N_{2}\left(c_{1}^{l},-e_{1}^{l} ; \rho\right)-\left(\frac{D_{l}}{Y_{t}}\right)^{2\left(r+\rho \sigma_{1}^{2}\right) / \sigma_{1}^{2}} \\
& \left.\left.\cdot\left[N_{2}\left(\bar{c}_{1}^{l-1},-\bar{e}_{1}^{l} ; \rho\right)-N_{2}\left(\bar{c}_{1}^{l},-\bar{e}_{1}^{l} ; \rho\right)\right]\right\}\right\} \\
& -e^{-r(T-t)}\left\{K_{d} N\left(\bar{d}_{d}\right)+\sum_{l=1}^{d}\left\{K_{l-1} N_{2}\left(c_{2}^{l-1, l},-e_{2}^{l} ; \rho\right)\right.\right. \\
& -K_{l} N_{2}\left(c_{2}^{l, l},-e_{2}^{l} ; \rho\right)-\left(\frac{D_{l}}{Y_{t}}\right)^{2 r / \sigma_{1}^{2}} \\
& \left.\left.\cdot\left[K_{l-1} N_{2}\left(\bar{c}_{2}^{l-1, l},-\bar{e}_{2}^{l} ; \rho\right)-K_{l} N_{2}\left(\bar{c}_{2}^{l, l},-\bar{e}_{2}^{l} ; \rho\right)\right]\right\}\right\} .
\end{aligned}
$$

3.4. Hedging the Outside-Reset Option. It is well known that hedge parameters (or Greeks) of options are very important in risk management of reset option. Of particular importance are the Delta and the Gamma, respectively, the rate of change of the option value with respect to the stock price, and the rate of change of the option Delta with respect to the stock price. Here, we provide the Delta and Gamma of the outsidereset option in Proposition 4. Other Greeks can be similarly derived. 
Proposition 4. The values at time t of $\Delta$ and $\Gamma$ for the outsidereset call option with $m$ predecided reset dates and $d$ strike resets, assuming the risky asset price given in (5), are given as follows:

$$
\begin{aligned}
\Delta & =N\left(d_{d}\right)+\sum_{l=1}^{d} \sum_{g=1}^{m}\left[N_{m+1}\left(D_{g}^{l, l-1} ; \Sigma_{g}\right)-N_{m+1}\left(D_{g}^{l, l} ; \Sigma_{g}\right)\right]+\frac{1}{\sigma_{2} \sqrt{T-t}} \\
& \cdot \sum_{l=1}^{d} \sum_{g=1}^{m}\left\{\left[\frac{\partial N_{m+1}\left(D_{g}^{l, l-1} ; \Sigma_{g}\right)}{\partial d_{l-1}}-\frac{\partial N_{m+1}\left(D_{g}^{l, l} ; \Sigma_{g}\right)}{\partial d_{l}}\right]-\frac{e^{-r(T-t)}}{S}\left[K_{l-1} \frac{\partial N_{m+1}\left(\bar{D}_{g}^{l, l-1} ; \Sigma_{g}\right)}{\partial \bar{d}_{l-1}}-K_{l} \frac{\partial N_{m+1}\left(\bar{D}_{g}^{l, l} ; \Sigma_{g}\right)}{\partial \bar{d}_{l}}\right]\right\}, \\
\Gamma= & \frac{1}{S \sigma_{2} \sqrt{T-t}}\left\{\frac{1}{\sqrt{2 \pi}} e^{-d_{d}^{2} / 2}+\sum_{l=1}^{d} \sum_{g=1}^{m}\left\{\left[\frac{\partial N_{m+1}\left(D_{g}^{l, l-1} ; \Sigma_{g}\right)}{\partial d_{l-1}}-\frac{\partial N_{m+1}\left(D_{g}^{l, l} ; \Sigma_{g}\right)}{\partial d_{l}}\right]+\frac{1}{\sigma_{2} \sqrt{T-t}}\right]+\frac{e^{-r(T-t)}}{S}\left[K_{l-1} \frac{\partial N_{m+1}\left(\bar{D}_{g}^{l, l-1} ; \Sigma_{g}\right)}{\partial \bar{d}_{l-1}}-K_{l} \frac{\partial N_{m+1}\left(\bar{D}_{g}^{l, l} ; \Sigma_{g}\right)}{\partial \bar{d}_{l}}\right]\right. \\
& \left.\cdot\left[\frac{\partial^{2} N_{m+1}\left(D_{g}^{l, l-1} ; \Sigma_{g}\right)}{\partial d_{l-1}^{2}}-\frac{\partial^{2} N_{m+1}\left(D_{g}^{l, l} ; \Sigma_{g}\right)}{\partial d_{l}^{2}}\right]\right\} . \\
& \left.\left.-\frac{e^{-r(T-t)}}{\sigma_{2} \sqrt{T-t}}\left[K_{l-1} \frac{\partial^{2} N_{m+1}\left(\bar{D}_{g}^{l, l-1} ; \Sigma_{g}\right)}{\partial \bar{d}_{l-1}^{2}}-K_{l} \frac{\partial^{2} N_{m+1}\left(\bar{D}_{g}^{l, l} ; \Sigma_{g}\right)}{\partial \bar{d}_{l}^{2}}\right]\right\}\right\}
\end{aligned}
$$

Proof. See Appendix B.

In order to describe clearly the phenomena of Delta and Gamma for the outside-reset option, in the following, we limit ourselves to considering the simple case for this option with one reset date. Then, we have

$$
\begin{gathered}
N_{2}(a, b ; \varrho)=\frac{1}{2 \pi \sqrt{1-\varrho^{2}}} \\
\cdot \int_{-\infty}^{a} \int_{-\infty}^{b} e^{-\left(x^{2}-2 \varrho x y+y^{2}\right) / 2\left(1-\varrho^{2}\right)} d x d y, \\
\frac{\partial N_{2}(a, b ; \varrho)}{\partial a}=\frac{1}{\sqrt{2 \pi}} e^{-a^{2} / 2} N\left(\frac{b-\varrho a}{\sqrt{1-\varrho^{2}}}\right),
\end{gathered}
$$

$$
\begin{gathered}
\frac{\partial^{2} N_{2}(a, b ; \varrho)}{\partial a^{2}}=\frac{1}{\sqrt{2 \pi}} e^{-a^{2} / 2}\left[-a N\left(\frac{b-\varrho a}{\sqrt{1-\varrho^{2}}}\right)\right. \\
\left.-\frac{\varrho}{\sqrt{2 \pi\left(1-\varrho^{2}\right)}} e^{-(b-\varrho a)^{2} / 2\left(1-\varrho^{2}\right)}\right]
\end{gathered}
$$

and the following corollary.

Corollary 5. The values at time $t$ of $\Delta$ and $\Gamma$ for the outsidereset call option with one reset date are, respectively, given by

$$
\begin{aligned}
\Delta & =N\left(d_{d}\right)+\sum_{l=1}^{d}\left\{\left[N_{2}\left(a_{l, 1}, d_{l-1} ; \varrho\right)-N_{2}\left(a_{l, 1}, d_{l} ; \varrho\right)\right]+\frac{1}{\sigma_{2} \sqrt{2 \pi(T-t)}}\left[e^{-d_{l-1}^{2} / 2} N\left(\frac{a_{l, 1}-\varrho d_{l-1}}{\sqrt{1-\varrho^{2}}}\right)-e^{-d_{l}^{2} / 2} N\left(\frac{a_{l, 1}-\varrho d_{l}}{\sqrt{1-\varrho^{2}}}\right)\right]\right. \\
& \left.-\frac{e^{-r(T-t)}}{S}\left[K_{l-1} e^{-\bar{d}_{l-1}^{2} / 2} N\left(\frac{\bar{a}_{l, 1}-\varrho \bar{d}_{l-1}}{\sqrt{1-\varrho^{2}}}\right)-K_{l} e^{-\bar{d}_{l}^{2} / 2} N\left(\frac{\bar{l}_{l, 1}-\varrho \bar{d}_{l}}{\sqrt{1-\varrho^{2}}}\right)\right]\right\}, \\
\Gamma & =\frac{1}{S \sigma_{2} \sqrt{2 \pi(T-t)}}\left\{e^{-d_{d}^{2} / 2}+\sum_{l=1}^{d}\left\{\left[e^{-d_{l-1}^{2} / 2} N\left(\frac{a_{l, 1}-\varrho d_{l-1}}{\sqrt{1-\varrho^{2}}}\right)-e^{-d_{l}^{2} / 2} N\left(\frac{a_{l, 1}-\varrho d_{l}}{\sqrt{1-\varrho^{2}}}\right)\right]\right.\right. \\
& +\frac{1}{\sigma_{2} \sqrt{T-t}}\left[-d_{l-1} e^{-d_{l-1}^{2} / 2} N\left(\frac{a_{l, 1}-\varrho d_{l-1}}{\sqrt{1-\varrho^{2}}}\right)-\frac{\rho^{-\left(a_{l, 1}^{2}-2 \varrho a_{l, 1} d_{l-1}+d_{l-1}^{2}\right) / 2\left(1-\varrho^{2}\right)}}{\sqrt{2 \pi\left(1-\varrho^{2}\right)}}+d_{l} e^{-d_{l}^{2} / 2} N\left(\frac{a_{l, 1}-\varrho d_{l}}{\sqrt{1-\varrho^{2}}}\right)-\frac{\varrho e^{-\left(a_{l, 1}^{2}-2 \varrho a_{l, 1} d_{l}+d_{l}^{2}\right) / 2\left(1-\varrho^{2}\right)}}{\sqrt{2 \pi\left(1-\varrho^{2}\right)}}\right]
\end{aligned}
$$




$$
\begin{aligned}
& +\frac{e^{-r(T-t)}}{S}\left[K_{l-1} e^{-\bar{d}_{l-1}^{2} / 2} N\left(\frac{\bar{a}_{l, 1}-\varrho \bar{d}_{l-1}}{\sqrt{1-\varrho^{2}}}\right)-K_{l} e^{-\bar{d}_{l}^{2} / 2} N\left(\frac{\bar{a}_{l, 1}-\varrho \bar{d}_{l}}{\sqrt{1-\varrho^{2}}}\right)\right] \\
& \left.-\frac{e^{-r(T-t)}}{\sigma_{2} \sqrt{T-t}}\left[-\bar{d}_{l-1} K_{l-1} e^{-\bar{d}_{l-1}^{2} / 2} N\left(\frac{\bar{a}_{l, 1}-\varrho \bar{d}_{l-1}}{\sqrt{1-\varrho^{2}}}\right)+\bar{d}_{l} K_{l} e^{-\bar{d}_{l}^{2} / 2} N\left(\frac{\bar{a}_{l, 1}-\varrho \bar{d}_{l}}{\sqrt{1-\varrho^{2}}}\right)-\frac{\varrho K_{l-1} e^{-\left(\bar{a}_{l, 1}^{2}-2 \rho \bar{a}_{l, 1} \bar{d}_{l-1}+\bar{d}_{l-1}^{2}\right) / 2\left(1-\varrho^{2}\right)}}{\sqrt{2 \pi\left(1-\varrho^{2}\right)}}-\frac{\rho K_{l} e^{-\left(\bar{a}_{l, 1}^{2}-2 \varrho \bar{a}_{1,1} \bar{d}_{l}+\bar{d}_{l}^{2}\right) / 2\left(1-\varrho^{2}\right)}}{\sqrt{2 \pi\left(1-\varrho^{2}\right)}}\right]\right\},
\end{aligned}
$$

where $\varrho=\rho \sqrt{\left(t_{1}-t\right) /(T-t)}$ and $t_{1}$ is the reset date.

When $t \rightarrow t_{1}-$, then

$$
\begin{aligned}
N_{2}\left(a_{l, 1}, d_{l-1} ; \varrho\right) & \longrightarrow N\left(d_{l-1}\right), \\
\frac{1}{\sqrt{2 \pi}} e^{-d_{l}^{2} / 2} N\left(\frac{a_{l, 1}-\varrho d_{l}}{\sqrt{1-\varrho^{2}}}\right) & \left.\longrightarrow \frac{1}{\sqrt{2 \pi}} e^{-d_{l}^{2} / 2}\right|_{t=t_{1}}, \\
N_{2}\left(a_{l, 1}, d_{l} ; \varrho\right) & \longrightarrow 0 \\
\frac{1}{\sqrt{2 \pi}} e^{-\bar{d}_{l}^{2} / 2} N\left(\frac{a_{l, 1}-\varrho \bar{d}_{l}}{\sqrt{1-\varrho^{2}}}\right) & \left.\longrightarrow \frac{1}{\sqrt{2 \pi}} e^{-\bar{d}_{l}^{2} / 2}\right|_{t=t_{1}} .
\end{aligned}
$$

Consequently $\Delta$ and $\Gamma$ at time $t_{1}$ become as follows:

$$
\begin{aligned}
\Delta & =\left\{N\left(d_{0}\right)\right. \\
& \left.+\left[\frac{1}{\sigma_{2} \sqrt{2 \pi(T-t)}}-1\right]\left(e^{-d_{d}^{2} / 2}-e^{-d_{0}^{2} / 2}\right)\right\}_{t=t_{1}}, \\
\Gamma & =\frac{1}{S_{t} \sigma_{2} \sqrt{2 \pi(T-t)}}\left\{e^{-d_{0}^{2} / 2}+\left[\frac{1}{\sigma_{2} \sqrt{T-t}}-\sqrt{2 \pi}\right]\right. \\
& \left.\cdot\left(d_{d} e^{-d_{d}^{2} / 2}-d_{0} e^{-d_{0}^{2} / 2}\right)\right\}_{t=t_{1}} .
\end{aligned}
$$

However, $\Delta$ and $\Gamma$ at time $t>t_{1}$ are given as follows:

$$
\begin{aligned}
\Delta & =N\left(d_{0}\right) I_{\left(Y_{t_{1}} \geq D_{1}\right)}+\sum_{l=1}^{d-1} N\left(d_{l}\right) I_{\left(D_{l} \geq Y_{t_{1}} \geq D_{l+1}\right)} \\
& +N\left(d_{d}\right) I_{\left(Y_{t_{1}}<D_{d}\right)}, \\
\Gamma & =\frac{1}{S_{t} \sigma_{2} \sqrt{2 \pi(T-t)}}\left[e^{-d_{0}^{2} / 2} I_{\left(Y_{t_{1}} \geq D_{1}\right)}\right. \\
& \left.+\sum_{l=1}^{d-1} e^{-d_{l}^{2} / 2} I_{\left(D_{l} \geq Y_{t_{1}} \geq D_{l+1}\right)}+e^{-d_{d}^{2} / 2} I_{\left(Y_{t_{1}}<D_{d}\right)}\right] .
\end{aligned}
$$

From (25)-(26), we find that $\Delta$ and $\Gamma$ at time $t_{1}$ are continuous as a function of the stock price. Therefore, Delta and Gamma do not have significant jumps when the stock price goes across the reset dates because of using the external process as a reset trigger, and it makes outside-reset options more amenable to dynamic hedging. Figure 4 illustrates the phenomena at time $t_{1}$ of Delta and Gamma for the outsidereset options at various underlying stock prices and contrasts those with the general-reset option specified in (2) and (3) which is studied by Liao and Wang [25]. Assume $K_{0}=100$, $\sigma_{1}=\sigma_{2}=0.3, \rho=1, Y_{0}=100, r=0.05, T=1$ (year), and $t_{1}=3 / 12$ (year) and the current stock price is 100 . We consider the strike price of the outside-reset option will be adjusted to $80,70,60,50$, and 40 if the external variable $Y_{t}$ falls below 80, 70, 60, 50, and 40. As shown in Figure 4, the Delta and Gamma of the general-reset options will fluctuate dramatically and oscillate if the stock prices near strike resets. This shows that the general-reset option has the phenomena of Delta jump and Gamma jump across reset date. With the outside-reset design, however, the oscillations in the delta are replaced by a much smoother double U-shaped curve. This added continuity of delta around reset level greatly facilitates option holders to hedge outside-reset options dynamically by trading the underlying stock. Therefore, it is evident that the outside-reset option does not have Delta and Gamma jumps as the general-reset option.

Figure 5 plots the option Delta and Gamma of the outsidereset call option at time $t_{1}$ for different values of $Y_{0}$ shown in Figure 5, and other parameter values are similar to that in Figure 4. We can see that the option Delta and Gamma of the outside-reset calls are sensitive to the changes in $S$ and $Y$.

\section{Conclusion}

In this paper, we proposed an outside-reset option with multiple strike reset and reset dates determined by an external process which correlates to the underlying asset and provided analytical pricing formula for this option. We analyzed some characteristics of this option and the impacts of the external process on the option through numerical experiments. Besides, it is also shown that the outside-reset option does not have Delta and Gamma jumps as the generalreset option. This useful property reduces the hedging risk dramatically. The model may be seen as an extension of Liao and Wang [25] to include further realism by introducing the external process. Also the model could be extended to value a large class of path-dependent options with discrete monitoring. This extension still remains as future work. 


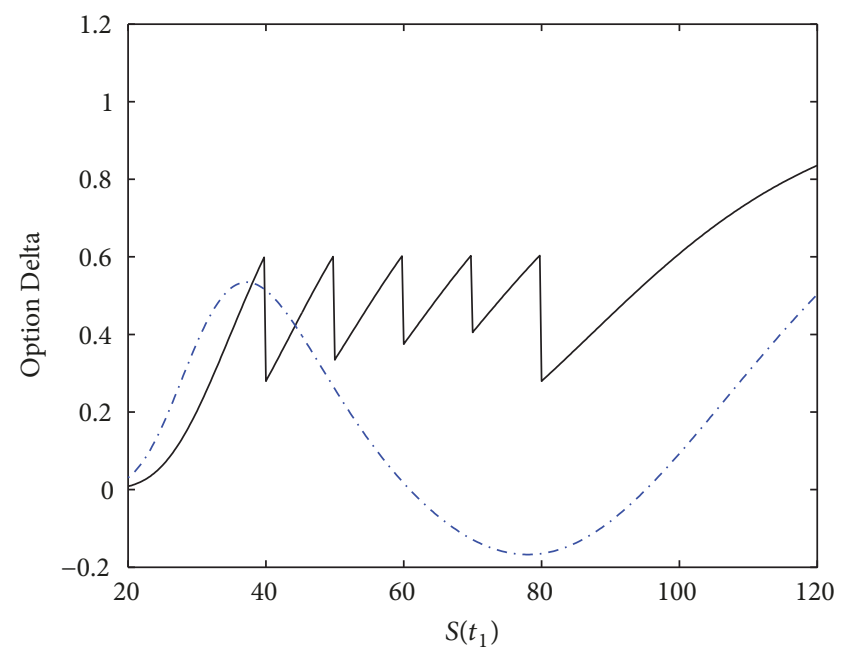

- General-reset option -..- Outside-reset option

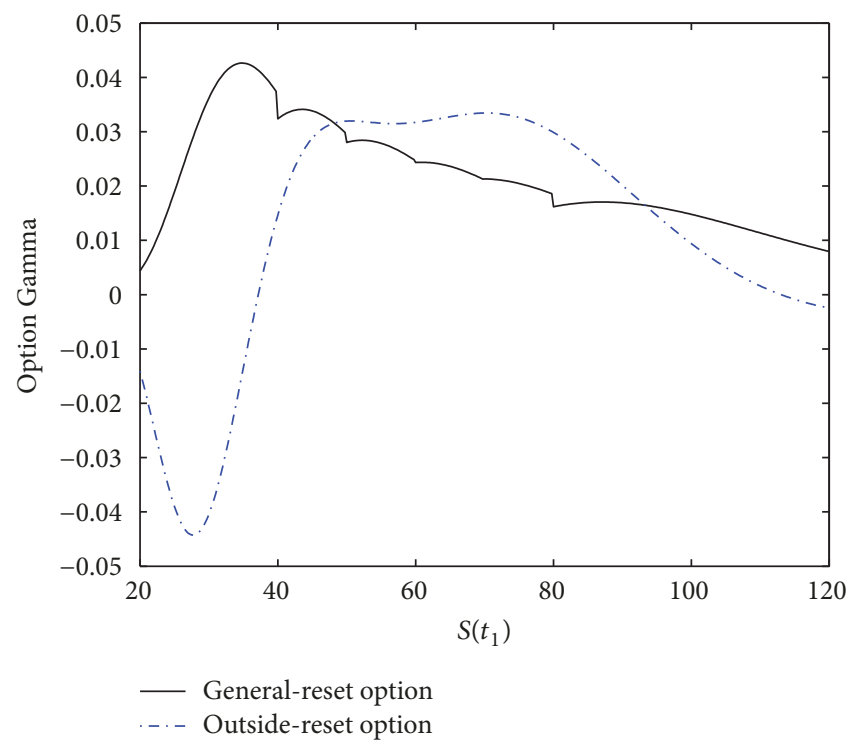

- General-reset option
..- Outside-reset option

FIgURE 4: Comparison of option $\Delta$ and $\Gamma$ between the general-reset option and outside-reset option.

\section{Appendix}

\section{A. The Proof of Proposition 1}

Since

$$
\begin{aligned}
& E_{t}^{Q}\left\{e^{-r(T-t)}\left(S_{T}-K_{h}\right)^{+} I_{A_{l}}\right\} \\
&=E_{t}^{Q}\left\{e^{-r(T-t)} S_{T} I_{\left(A_{l} \cap\left\{S_{T} \geq K_{h}\right\}\right)}\right\} \\
&-K_{h} E_{t}^{Q}\left\{e^{-r(T-t)} I_{\left(A_{l} \cap\left\{S_{T} \geq K_{h}\right\}\right)}\right\} \\
&= E_{t}^{Q}\left\{e^{-r(T-t)} S_{T} I_{\left(A_{l} \cap\left\{S_{T} \geq K_{h}\right\}\right)}\right\} \\
&-K_{h} e^{-r(T-t)} Q\left(A_{l} \cap\left\{S_{T} \geq K_{h}\right\}\right),
\end{aligned}
$$

according to Geman et al. [32], in order to simplify calculations, we change numeraire. For the first term we choose the stock price $S$ as numeraire and switch measure $Q$ to $Q_{1}$. The Radon-Nikodym derivative is then given by

$$
\left.\frac{d Q_{1}}{d Q}\right|_{\mathscr{F}_{T}}=e^{-r(T-t)} \frac{S_{T}}{S_{t}}=e^{-(1 / 2) \sigma_{2}^{*} \sigma_{2}^{* \top}(T-t)+\sigma_{2}^{*} W_{T-t}},
$$

where $\sigma_{2}^{*}=\left(\rho \sigma_{2}, \sigma_{2} \sqrt{1-\rho^{2}}\right)$ and $Q_{1}$ is again a martingale measure. By Girsanov's theorem, defined by

$$
\begin{aligned}
& \widetilde{W}_{t}^{1}=W_{t}^{1}-\rho \sigma_{2} t \\
& \widetilde{W}_{t}^{2}=W_{t}^{2}-\sigma_{2} \sqrt{1-\rho^{2}} t
\end{aligned}
$$

two independent Brownian motions are under $Q_{1}$. Under the new measure $Q_{1}$, the option price (A.1) can be restated as

$$
\begin{aligned}
E_{t}^{Q} & \left\{e^{-r(T-t)}\left(S_{T}-K_{h}\right)^{+} I_{A_{l}}\right\} \\
= & S_{t} Q_{1}\left(A_{l} \cap\left\{S_{T} \geq K_{h}\right\}\right) \\
& \quad-K_{h} e^{-r(T-t)} Q\left(A_{l} \cap\left\{S_{T} \geq K_{h}\right\}\right) .
\end{aligned}
$$

Now we need to calculate two probabilities of (A.4), respectively. First we have

$$
\begin{aligned}
& Q_{1}\left(A_{l} \cap\left\{S_{T} \geq K_{h}\right\}\right)=Q_{1}\left(\left\{\min \left[Y_{t_{1}}, Y_{t_{2}}, \ldots, Y_{t_{m}}\right]\right.\right. \\
& \left.\left.\geq D_{l}\right\} \cap\left\{S_{T} \geq K_{h}\right\}\right)=\sum_{g=1}^{m} Q_{1}\left(Y_{t_{g}} \geq D_{l}, Y_{t_{j}}\right. \\
& \left.\geq Y_{t_{g}}, j \neq g, j=1,2, \ldots, m, S_{T} \geq K_{h}\right) \\
& =\sum_{g=1}^{m} Q_{1}\left(\ln Y_{t_{g}} \geq \ln D_{l}, \ln Y_{t_{j}} \geq \ln Y_{t_{g}}, j \neq g, j\right. \\
& \left.=1, \ldots, m, \ln S_{T} \geq \ln K_{h}\right) .
\end{aligned}
$$

In terms of (A.3) and (A.4), then

$$
\begin{gathered}
Q_{1}\left(\ln Y_{t_{g}} \geq \ln D_{l}, \ln Y_{t_{j}} \geq \ln Y_{t_{g}}, j \neq g, j\right. \\
\left.\quad=1,2, \ldots, m, \ln S_{T} \geq \ln K_{h}\right) \\
\quad=Q_{1}\left(-\sigma_{1}\left(\widetilde{W}_{t_{g}}^{1}-\widetilde{W}_{t}^{1}\right) \leq \ln \frac{Y_{t}}{D_{l}}\right.
\end{gathered}
$$



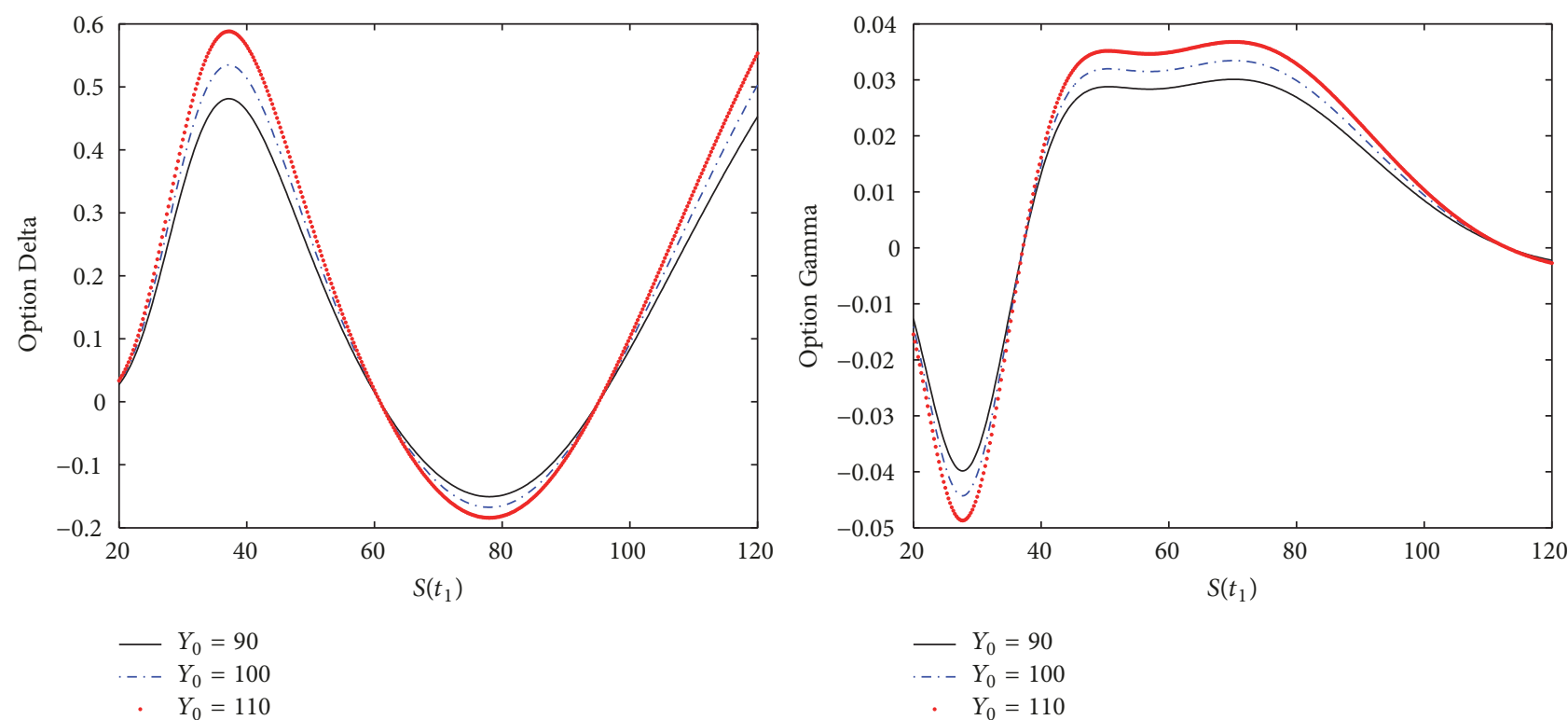

Figure 5: Option $\Delta$ and $\Gamma$ at time $t_{1}$ for different $Y_{0}$.

$$
\begin{aligned}
& +\left(r-\frac{1}{2} \sigma_{1}^{2}+\rho \sigma_{1} \sigma_{2}\right)\left(t_{g}-t\right) \\
& -\sigma_{1}\left(\widetilde{W}_{t_{j}}^{1}-\widetilde{W}_{t_{g}}^{1}\right) \\
& \leq\left(r-\frac{1}{2} \sigma_{1}^{2}+\rho \sigma_{1} \sigma_{2}\right)\left(t_{j}-t_{g}\right), j \neq g, j \\
& =1,2, \ldots, m,-\rho \sigma_{2}\left(\widetilde{W}_{T}^{1}-\widetilde{W}_{t}^{1}\right) \\
& -\sqrt{1-\rho^{2}} \sigma_{2}\left(\widetilde{W}_{T}^{2}-\widetilde{W}_{t}^{2}\right) \leq \ln \frac{S_{t}}{K_{h}}
\end{aligned}
$$

$$
\begin{aligned}
& \left.+\left(r+\frac{1}{2} \sigma_{2}^{2}\right)(T-t)\right)=Q_{1}\left(Z_{1} \leq b_{g, 1}, \ldots, Z_{g-1}\right. \\
& \leq b_{g, g-1}, Z_{g} \leq a_{l, g}, Z_{g+1} \leq b_{g, g+1}, \ldots, Z_{m} \\
& \left.\leq b_{g, m}, Z_{m+1} \leq d_{h}\right)=N_{m+1}\left(D_{g}^{l, h} ; \Sigma_{g}\right)
\end{aligned}
$$

where $Z_{j}, j=1,2, \ldots, m+1$, are defined by

$$
Z_{j}= \begin{cases}\frac{\widetilde{W}_{t_{g}}^{1}-\widetilde{W}_{t_{j}}^{1}}{\sqrt{t_{g}-t_{j}}}, & j=1,2, \ldots, g-1, \\ -\frac{\widetilde{W}_{t_{g}}^{1}-\widetilde{W}_{t}^{1}}{\sqrt{t_{g}-t}}, & j=g, \\ \widetilde{W}_{t_{j}}^{1}-\widetilde{W}_{t_{g}}^{1} & j=g+1, \ldots, m, \\ -\frac{\rho{ }_{t_{j}-t_{g}}}{\rho\left(\widetilde{W}_{T}^{1}-\widetilde{W}_{t}^{1}\right)+\sqrt{1-\rho^{2}}\left(\widetilde{W}_{T}^{2}-\widetilde{W}_{t}^{2}\right)} & j=m+1 \\ -\frac{\sqrt{T-t}}{} & j=\end{cases}
$$

and $\Sigma_{g}=\left(\rho_{k, j}^{g}\right)_{(m+1) \times(m+1)}$ with $\rho_{k, j}^{g}=E\left[Z_{k} Z_{j}\right]$. Similar to the argument technique above, we get

$$
Q\left(A_{l} \cap\left\{S_{T} \geq K_{h}\right\}\right)=\sum_{g=1}^{m} N_{m+1}\left(\bar{D}_{g}^{l, h} ; \Sigma_{g}\right) .
$$

This completes the proof of Proposition 1.

\section{B. The Proof of Proposition 4}

Because the derivatives

$$
\begin{aligned}
& \frac{\partial N_{m+1}\left(D_{g}^{l, h} ; \Sigma_{g}\right)}{\partial S}=\frac{\partial N_{m+1}\left(D_{g}^{l, h} ; \Sigma_{g}\right)}{\partial d_{h}} \cdot \frac{\partial d_{h}}{\partial S}, \\
& \frac{\partial N_{m+1}\left(\bar{D}_{g}^{l, h} ; \Sigma_{g}\right)}{\partial S}=\frac{\partial N_{m+1}\left(\bar{D}_{g}^{l, h} ; \Sigma_{g}\right)}{\partial \bar{d}_{h}} \cdot \frac{\partial \bar{d}_{h}}{\partial S},
\end{aligned}
$$


where $\partial d_{h} / \partial S=1 / S \sigma_{2} \sqrt{T-t}=\partial \bar{d}_{h} / \partial S, h=1,2, \ldots, d$, therefore, the Delta of the outside-reset option is given by

$$
\begin{aligned}
& \Delta=\frac{\partial \mathrm{ORC}(t)}{\partial S} \\
& =N\left(d_{d}\right)+\sum_{l=1}^{d} \sum_{g=1}^{m}\left[N_{m+1}\left(D_{g}^{l, l-1} ; \Sigma_{g}\right)-N_{m+1}\left(D_{g}^{l, l} ; \Sigma_{g}\right)\right] \\
& +S_{t}\left\{\frac{\partial N\left(d_{d}\right)}{\partial d_{d}} \frac{\partial d_{d}}{\partial S}+\sum_{l=1}^{d} \sum_{g=1}^{m}\left[\frac{\partial N_{m+1}\left(D_{g}^{l, l-1} ; \Sigma_{g}\right)}{\partial d_{l-1}} \frac{\partial d_{l-1}}{\partial S}-\frac{\partial N_{m+1}\left(D_{g}^{l, l} ; \Sigma_{g}\right)}{\partial d_{l}} \frac{\partial d_{l}}{\partial S}\right]\right\} \\
& -e^{-r(T-t)}\left\{K_{d} \frac{\partial N\left(\bar{d}_{d}\right)}{\partial \bar{d}_{d}} \frac{\partial \bar{d}_{d}}{\partial S}+\sum_{l=1}^{d} \sum_{g=1}^{m}\left[K_{l-1} \frac{\partial N_{m+1}\left(\bar{D}_{g}^{l, l-1} ; \Sigma_{g}\right)}{\partial \bar{d}_{l-1}} \frac{\partial \bar{d}_{l-1}}{\partial S}-K_{l} \frac{\partial N_{m+1}\left(\bar{D}_{g}^{l, l} ; \Sigma_{g}\right)}{\partial \bar{d}_{l}} \frac{\partial \bar{d}_{l}}{\partial S}\right]\right\} \\
& =N\left(d_{d}\right)+\sum_{l=1}^{d} \sum_{g=1}^{m}\left[N_{m+1}\left(D_{g}^{l, l-1} ; \Sigma_{g}\right)-N_{m+1}\left(D_{g}^{l, l} ; \Sigma_{g}\right)\right] \\
& +\frac{1}{\sigma_{2} \sqrt{T-t}}\left\{\frac{\partial N\left(d_{d}\right)}{\partial d_{d}}+\sum_{l=1}^{d} \sum_{g=1}^{m}\left[\frac{\partial N_{m+1}\left(D_{g}^{l, l-1} ; \Sigma_{g}\right)}{\partial d_{l-1}}-\frac{\partial N_{m+1}\left(D_{g}^{l, l} ; \Sigma_{g}\right)}{\partial d_{l}}\right]\right\} \\
& -\frac{e^{-r(T-t)}}{S \sigma_{2} \sqrt{T-t}}\left\{K_{d} \frac{\partial N\left(\bar{d}_{d}\right)}{\partial \bar{d}_{d}}+\sum_{l=1}^{d} \sum_{g=1}^{m}\left[K_{l-1} \frac{\partial N_{m+1}\left(\bar{D}_{g}^{l, l-1} ; \Sigma_{g}\right)}{\partial \bar{d}_{l-1}}-K_{l} \frac{\partial N_{m+1}\left(\bar{D}_{g}^{l, l} ; \Sigma_{g}\right)}{\partial \bar{d}_{l}}\right]\right\} \text {. }
\end{aligned}
$$

Notice that $\partial N(x) / \partial x=(1 / \sqrt{2 \pi}) e^{-x^{2} / 2}$. Rearranging (B.2) then yields formula (16). Similar to (B.2), we also have the Gamma of the outside-reset option as follows:

$$
\begin{aligned}
\Gamma & =\frac{\partial^{2} \mathrm{ORC}(t)}{\partial S^{2}}=\frac{1}{S \sigma_{2} \sqrt{T-t}}\left\{\frac{\partial N\left(d_{d}\right)}{\partial d_{d}}+\sum_{l=1}^{d} \sum_{g=1}^{m}\left\{\left[\frac{\partial N_{m+1}\left(D_{g}^{l, l-1} ; \Sigma_{g}\right)}{\partial d_{l-1}}-\frac{\partial N_{m+1}\left(D_{g}^{l, l} ; \Sigma_{g}\right)}{\partial d_{l}}\right]+\frac{1}{\sigma_{2} \sqrt{T-t}}\right.\right. \\
& \cdot\left[\frac{\partial^{2} N_{m+1}\left(D_{g}^{l, l-1} ; \Sigma_{g}\right)}{\partial d_{l-1}^{2}}-\frac{\partial^{2} N_{m+1}\left(D_{g}^{l, l} ; \Sigma_{g}\right)}{\partial d_{l}^{2}}\right]+\frac{e^{-r(T-t)}}{S}\left[K_{l-1} \frac{\partial N_{m+1}\left(\bar{D}_{g}^{l, l-1} ; \Sigma_{g}\right)}{\partial \bar{d}_{l-1}}-K_{l} \frac{\partial N_{m+1}\left(\bar{D}_{g}^{l, l} ; \Sigma_{g}\right)}{\partial \bar{d}_{l}}\right] \\
& \left.\left.-\frac{e^{-r(T-t)}}{\sigma_{2} \sqrt{T-t}}\left[K_{l-1} \frac{\partial^{2} N_{m+1}\left(\bar{D}_{g}^{l, l-1} ; \Sigma_{g}\right)}{\partial \bar{d}_{l-1}^{2}}-K_{l} \frac{\partial^{2} N_{m+1}\left(\bar{D}_{g}^{l, l} ; \Sigma_{g}\right)}{\partial \bar{d}_{l}^{2}}\right]\right\}\right\} .
\end{aligned}
$$

By observing (B.2) and (B.3), we see the key elements for computing Delta and Gamma are $\partial N_{m+1}\left(D_{g}^{l, h} ; \Sigma_{g}\right) / \partial a_{l, g}$, $\partial N_{m+1}\left(D_{g}^{l, h} ; \Sigma_{g}\right) / \partial b_{g, j}, \partial N_{m+1}\left(D_{g}^{l, h} ; \Sigma_{g}\right) / \partial d_{h}$, and $\partial^{2} N_{m+1}\left(D_{g}^{l, h} ;\right.$ $\left.\Sigma_{g}\right) / \partial d_{h}^{2}$ 


\section{Conflicts of Interest}

The authors declare that there are no conflicts of interest regarding the publication of this paper.

\section{Acknowledgments}

The authors would like to thank participants at the 15 th International Conference on Financial Systems Engineering and Risk Management (FSERM'2017) for valuable comments on an earlier version of this work. This work was supported by the NSF of China (Grant no. 11461008).

\section{References}

[1] P. P. Boyle, A. W. Kolkiewicz, and K. S. Tan, "Valuation of the reset options embedded in some equity-linked insurance products," North American Actuarial Journal, vol. 5, no. 3, pp. $1-18,2001$.

[2] S. F. Gray and R. E. Whaley, "Valuing S\&P 500 bear market warrants with a periodic reset," The Journal of Derivatives, vol. 5, no. 1, pp. 99-106, 1997.

[3] S. F. Gray and R. E. Whaley, "Reset put options: Valuation, risk characteristics, and an application," Australian Journal of Management, vol. 24, no. 1, pp. 1-20, 1999.

[4] L. P. Hsueh and B. H. Guo, "Reset warrants: Design and valuation," Journal of Financial Studies, vol. 6, no. 2, pp. 1-18, 1998.

[5] W.-Y. Cheng and S. Zhang, "The analytics of reset options," The Journal of Derivatives, vol. 8, no. 1, pp. 59-71, 2000.

[6] S. J. Li, S. H. Li, and C. Sun, "A generalization of reset options pricing formulae with stochastic interest rates," Research in International Business and Finance, vol. 21, no. 2, pp. 119-133, 2007.

[7] Y. H. Liu, I. M. Jiang, S. H. Lee, and Y. T. Cheng, "The valuation of reset options when underlying assets are autocorrelated," International Journal of Business and Finance Research, vol. 5, no. 2, pp. 95-114, 2011.

[8] A. François-Heude and O. Yousfi, "A generalization of Gray and Whaley's reset option," Journal of Asset Management, vol. 16, no. 4, pp. 223-235, 2015.

[9] M. Dai, Y. K. Kwok, and L. X. Wu, “Options with multiple reset rights," International Journal of Theoretical and Applied Finance, vol. 6, no. 6, pp. 637-653, 2003.

[10] M. Dai, Y. K. Kwok, and L. Wu, "Optimal shouting policies of options with strike reset right," Mathematical Finance, vol. 14, no. 3, pp. 383-401, 2004.

[11] M. Dai and Y. K. Kwok, "Options with combined reset rights on strike and maturity," Journal of Economic Dynamics \& Control, vol. 29, no. 9, pp. 1495-1515, 2005.

[12] Z. Yang, F. Yi, and M. Dai, "A parabolic variational inequality arising from the valuation of strike reset options," Journal of Differential Equations, vol. 230, no. 2, pp. 481-501, 2006.

[13] J. Goard, "Exact solutions for a strike reset put option and a shout call option," Mathematical and Computer Modelling, vol. 55, no. 5-6, pp. 1787-1797, 2012.

[14] L. P. Hsueh and Y. A. Liu, "Step-Reset Options: Design and Valuation," Journal of Futures Markets, vol. 22, no. 2, pp. 155171, 2002.

[15] E. C. Yu and W. T. Shaw, "On the valuation of derivatives with snapshot reset features," International Journal of Theoretical and Applied Finance, vol. 11, no. 8, pp. 905-941, 2008.
[16] C.-H. Kao and Y.-D. Lyuu, "Pricing of moving-average-type options with applications," Journal of Futures Markets, vol. 23, no. 5, pp. 415-440, 2003.

[17] S.-L. Liao and C.-W. Wang, "Pricing arithmetic average reset options with control variates," The Journal of Derivatives, vol. 10, no. 2, pp. 59-74, 2002.

[18] I. J. Kim, G. H. Chang, and S. J. Byun, "Valuation of arithmetic average reset options," The Journal of Derivatives, vol. 11, no. 1, pp. $70-80,2003$.

[19] C.-C. Chang, S.-L. Chung, and M. B. Shackleton, "Pricing options with American-style average reset features," Quantitative Finance, vol. 4, no. 3, pp. 292-300, 2004.

[20] T.-S. Dai, Y.-Y. Fang, and Y.-D. Lyuu, "Analytics for geometric average trigger reset options," Applied Economics Letters, vol. 12, no. 13, pp. 835-840, 2005.

[21] M. Costabile, I. Massabo, and E. Russo, "A binomial model for pricing US-style average options with reset features," International Journal of Financial Markets and Derivatives, vol. 1, no. 3, p. 258, 2010.

[22] M. Costabile, I. Massabó, and E. Russo, "On pricing arithmetic average reset options with multiple reset dates in a lattice framework," Journal of Computational and Applied Mathematics, vol. 235, no. 17, pp. 5307-5325, 2011.

[23] Y. Hsiao, "A Simple Method to Price Window Reset Options," Journal of Mathematical Finance, vol. 3, no. 1, pp. 96-102, 2013.

[24] S. N. Chen and I. M. Jiang, "Quanto reset put options," Journal of Accounting Finance \& Management Strategy, vol. 11, no. 1, pp. 19-28, 2016.

[25] S.-L. Liao and C.-W. Wang, "The valuation of reset options with multiple strike resets and reset dates," Journal of Futures Markets, vol. 23, no. 1, pp. 87-107, 2003.

[26] R. Heynen and H. Kat, “Crossing barrier," Risk, vol. 7, pp. 46-51, 1994.

[27] Y. Kwok, L. Wu, and H. Yu, "Pricing Multi-Asset Options with an External Barrier," International Journal of Theoretical and Applied Finance, vol. 1, no. 4, pp. 523-541, 1998.

[28] P. G. Zhang, "A unified formula for outside barrier options," Journal of Fiancial Engineering, vol. 4, pp. 335-347, 1995.

[29] A. Genz, "Numerical computation of multivariate normal probabilities," Journal of Computational and Graphical Statistics, vol. 1, no. 2, pp. 141-149, 1992.

[30] P. P. Boyle, Y. Lai, and K. S. Tan, "Pricing options using lattice rules," North American Actuarial Journal, vol. 9, no. 3, pp. 50-76, 2005.

[31] Y. Lai, "Intermediate rank lattice rules and applications to finance," Applied Numerical Mathematics, vol. 59, no. 1, pp. 120, 2009.

[32] H. Geman, N. E. Karoui, and J. Rochet, "Changes of numeraire, change of probability measure and option pricing," Journal of Applied Probability, vol. 32, no. 2, pp. 443-458, 1995. 


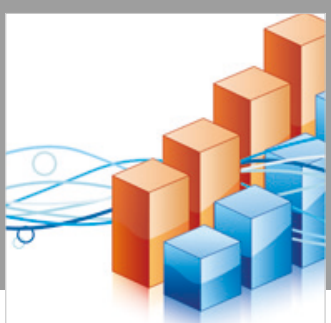

Advances in

Operations Research

\section{-n-m}
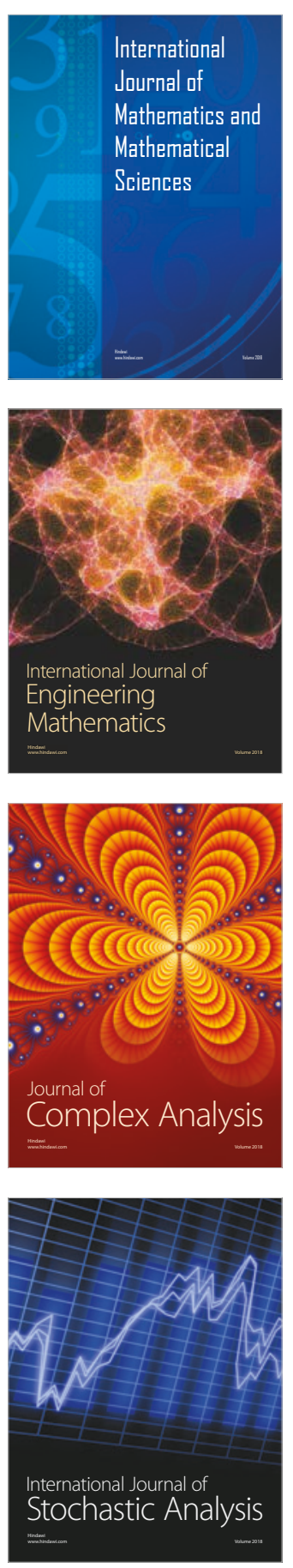
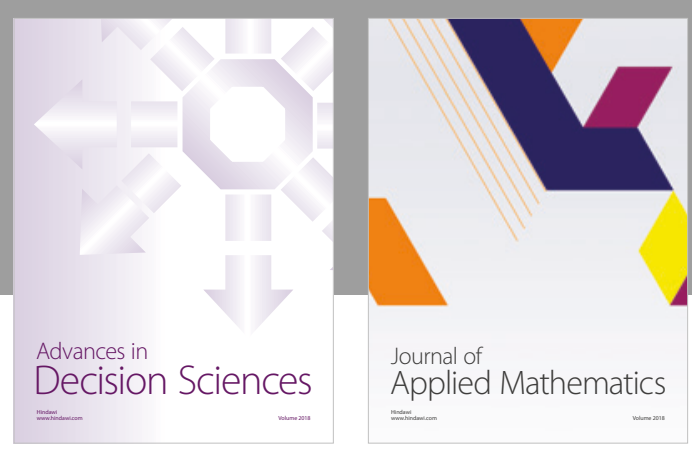

Journal of

Applied Mathematics
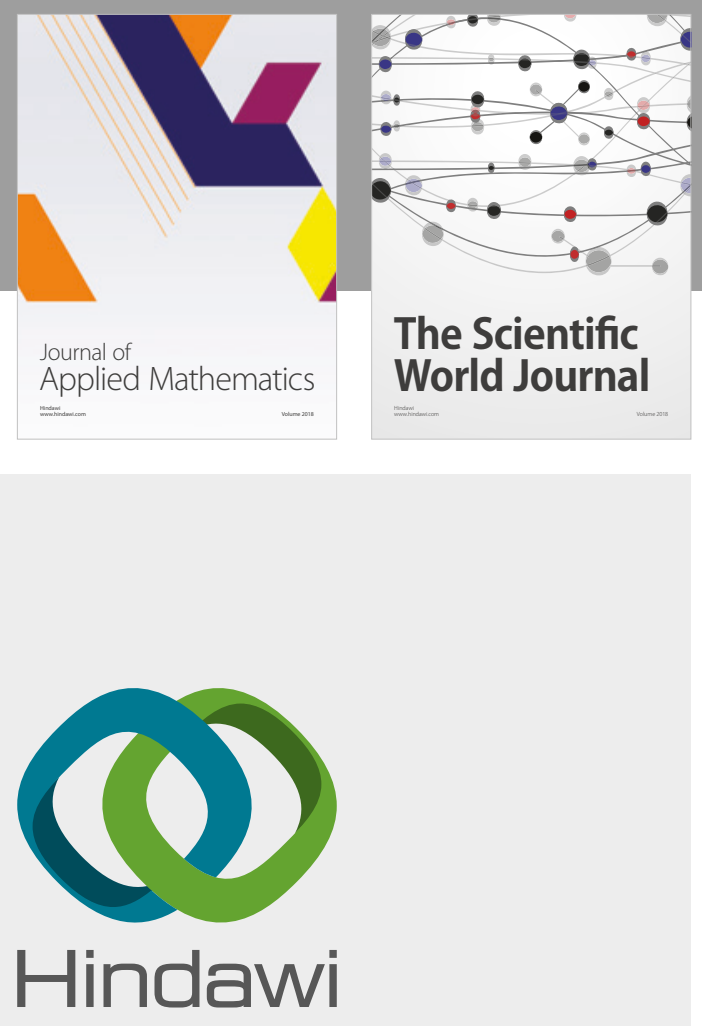

Submit your manuscripts at

www.hindawi.com

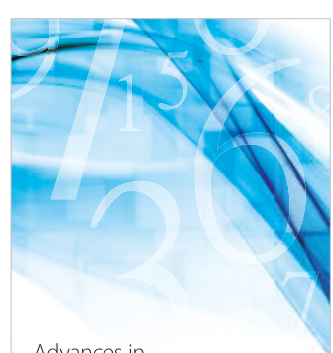

Advances in
Numerical Analysis
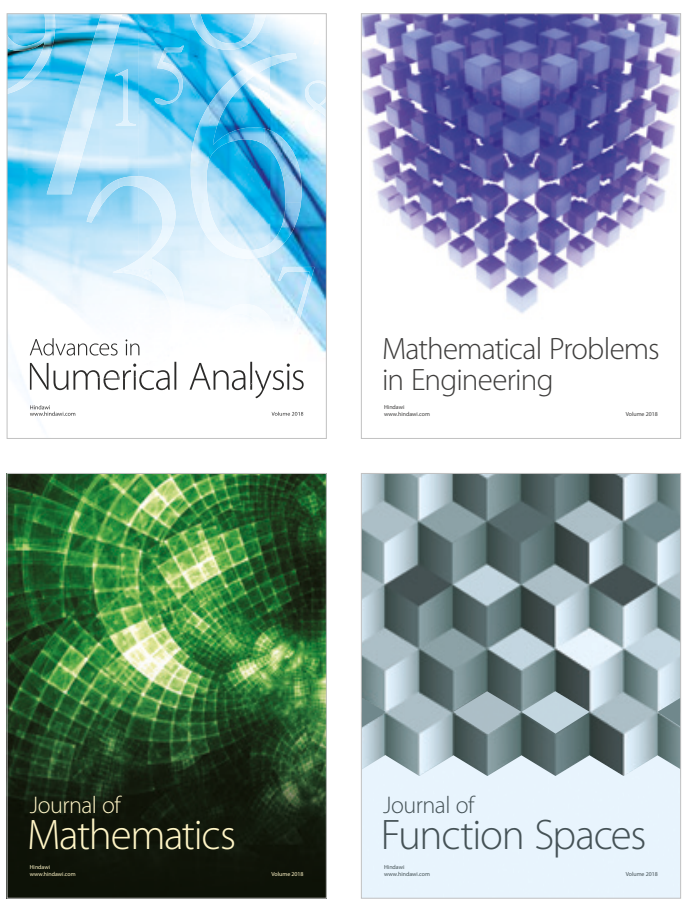

Mathematical Problems in Engineering

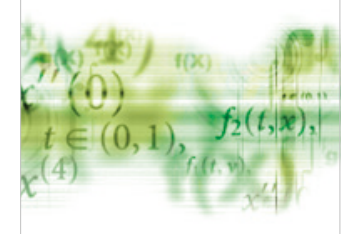

International Journal of

Differential Equations

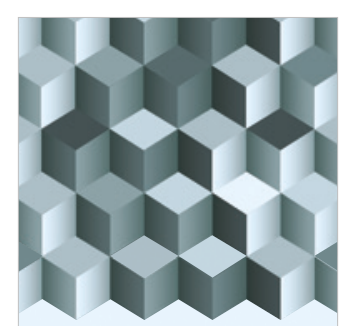

Journal of

Function Spaces
The Scientific

World Journal

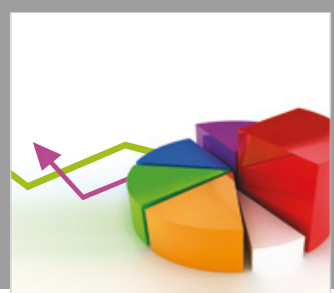

Journal of

Probability and Statistics
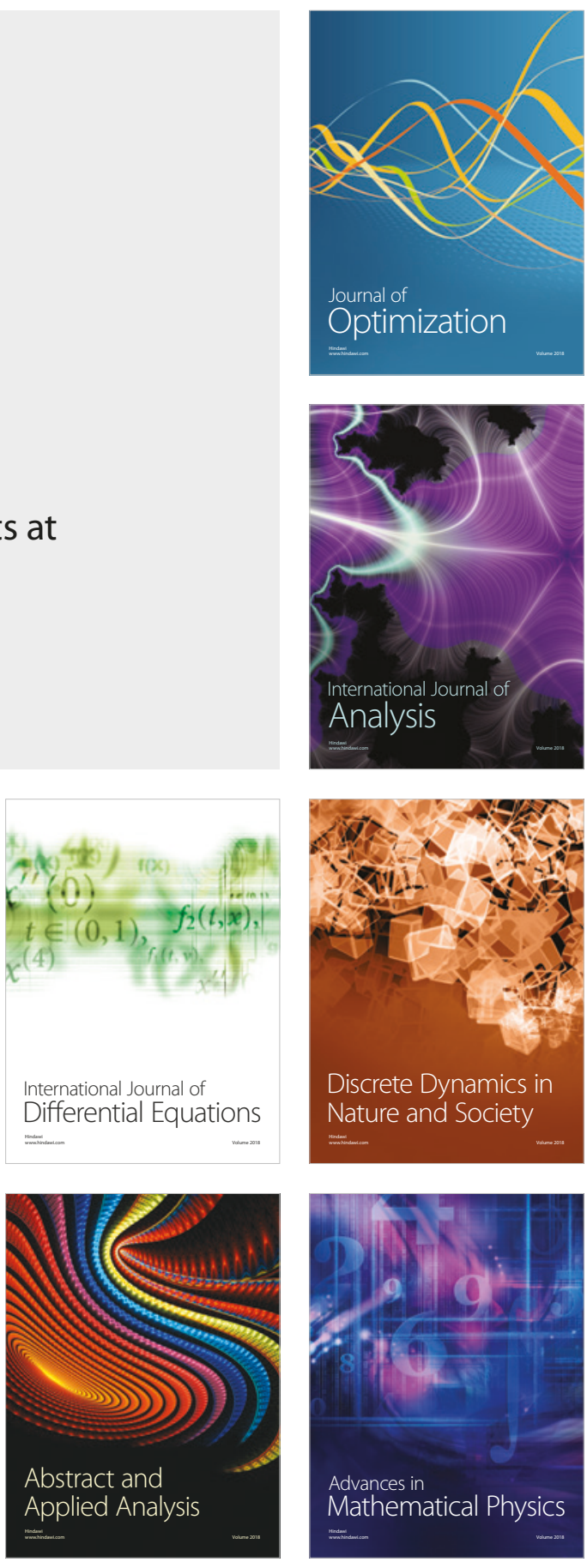